\title{
Arg Kinase Regulates Prefrontal Dendritic Spine Refinement and Cocaine-Induced Plasticity
}

\author{
Shannon L. Gourley, ${ }^{1,2,6}$ Anastasia Olevska, ${ }^{1}$ M. Sloan Warren, ${ }^{2,3}$ Jane R. Taylor, ${ }^{1,3,4}$ and Anthony J. Koleske ${ }^{2,3,5}$ \\ ${ }^{1}$ Department of Psychiatry, Division of Molecular Psychiatry, ${ }^{2}$ Department of Molecular Biophysics and Biochemistry, ${ }^{3}$ Interdepartmental Neuroscience \\ Program, Departments of ${ }^{4}$ Psychology and ${ }^{5}$ Neurobiology, Yale University, New Haven, Connecticut 06520, and ${ }^{6}$ Department of Pediatrics, Yerkes National \\ Primate Research Center, Emory University, Atlanta, Georgia 30329
}

Adolescence is characterized by vulnerability to the development of neuropsychiatric disorders including drug addiction, as well as prefrontal cortical refinement that culminates in structural stability in adulthood. Neuronal refinement and stabilization are hypothesized to confer resilience to poor decision making and addictive-like behaviors, although intracellular mechanisms are largely unknown. We characterized layer $\mathrm{V}$ prefrontal dendritic spine development and refinement in adolescent wild-type mice and mice lacking the cytoskeletal regulatory protein Abl-related gene (Arg) kinase. Relative to hippocampal CA1 pyramidal neurons, which exhibited a nearly linear increase in spine density up to postnatal day 60 (P60), wild-type prefrontal spine density peaked at P31, and then declined by $18 \%$ by $\mathrm{P} 56$-P60. In contrast, dendritic spines in mice lacking Arg destabilized by P31, leading to a net loss in both structures. Destabilization corresponded temporally to the emergence of exaggerated psychomotor sensitivity to cocaine. Moreover, cocaine reduced dendritic spine density in wild-type orbitofrontal cortex and enlarged remaining spine heads, but arg $^{-1-}$ spines were unresponsive. Local application of Arg or actin polymerization inhibitors exaggerated cocaine sensitization, as did reduced gene dosage of the Arg substrate, p190RhoGAP. Genetic and pharmacological Arg inhibition also retarded instrumental reversal learning and potentiated responding for reward-related cues, providing evidence that Arg regulates both psychomotor sensitization and decision-making processes implicated in addiction. These findings also indicate that structural refinement in the adolescent orbitofrontal cortex mitigates psychostimulant sensitivity and support the emerging perspective that the structural response to cocaine may, at any age, have behaviorally protective consequences.

\section{Introduction}

Adolescence is characterized by increased risk taking, vulnerability to the development of neuropsychiatric disorders such as drug addiction, and activity-dependent neocortical refinement that culminates in synaptic reorganization and dendritic spine pruning by early adulthood (Bourgeois et al., 1994; Rakic et al., 1994; Anderson et al., 1995; Spear, 2000; Chambers et al., 2003; Bhatt et al., 2009). Synapse and spine stabilization processes may impose a biological "set point" for prefrontal cortical-dependent neuropsychiatric vulnerabilities (Garey, 2010) and cognitive capacity in adult-

\footnotetext{
Received May 18, 2011; revised Dec. 14, 2011; accepted Dec. 23, 2011.

Author contributions: S.L.G., M.S.W., J.R.T., and A.J.K. designed research; S.L.G. and A.O. performed research; S.L.G. and J.R.T. analyzed data; S.L.G., J.R.T., and A.J.K. wrote the paper.

This work was supported by the Connecticut Mental Health and Addiction Services, Children's Healthcare of Atlanta, the Interdisciplinary Research Consortium on Stress, Self-Control, and Addiction (IRCSSA) (Grant UL1DE19586 and NIH Roadmap for Medical Research/Common Fund Grant AA017537), and the IRCSSA Interdisciplinary Research Education [RL5; Carolyn M. Mazure (Yale University, New Haven, CT), principal investigator] Program Grant 1RL5DA024858. We also acknowledge United States Public Health Service Grants NS039475, CA133346 (A.J.K.), DA027844, and DA011717 (J.R.T.). A.J.K. is an Established Investigator of the American Heart Association. We thank Drs. G. Aghajanian, A. Nairn, and Y.-C. Lin for advice and feedback, and X.-Y. Ye, J. Gordon, and M. Kerrisk for their valuable assistance. We are grateful to Dr. W. Bornmann for STI-571, Dr. J. Settleman for p190RhoGAP mutant mice, and Dr. S. Goff for Abl mutant mice.

The authors declare no competing financial interests.

Correspondence should be addressed to Anthony J. Koleske, 333 Cedar Street, SHMC-E31, New Haven, CT 06520 8024. E-mail: anthony.koleske@yale.edu.

DOI:10.1523/JNEUROSCI.2730-11.2012

Copyright $\odot 2012$ the authors $\quad 0270-6474 / 12 / 322314-10 \$ 15.00 / 0$
}

hood (Crews et al., 2007), and structural stabilization is hypothesized to confer resilience to impulsive decision making, addiction, and addictive-like behaviors in the transition from adolescence to adulthood (Spear, 2000; Chambers et al., 2003). With regard to addiction vulnerability, structural refinement and neuronal stability within the orbital compartment of the prefrontal cortex (oPFC) may be particularly impactful; classically associated with reward-related behavioral flexibility (Butter et al., 1963), the oPFC is widely implicated in cognitive and psychomotor sensitivity to amphetamine-like psychostimulants (Jentsch and Taylor, 1999; Schoenbaum et al., 2004; Homayoun and Moghaddam, 2006, 2008).

Under some circumstances, oPFC volume and dendritic spines atrophy in response to psychostimulants (Crombag et al., 2005; Singer et al., 2009; Muhammad and Kolb, 2011a,b). Structural atrophy may contribute to decreased oPFC glucose utilization after even short-term cocaine exposure in monkeys (Porrino et al., 2002), as well as diminished oPFC gray matter and cognitive flexibility in long-term cocaine addicts (Franklin et al., 2002; Ersche et al., 2008). Nonetheless, studies addressing whether biological events that compromise dendritic spine stability increase vulnerability to cocaine have largely focused on the ventral striatum (Norrholm et al., 2003; Lee et al., 2006; Shen et al., 2009; Kiraly et al., 2010). This may in part be due to the technical difficulties associated with deep-layer oPFC structural analyses (Kolb et al., 2008).

We used transgenic mice that express green fluorescent protein (GFP) in layer $\mathrm{V}$ oPFC to characterize postnatal dendritic 
spine development and refinement: Spine density peaks at P31, the equivalent of early adolescence in mice (Spear, 2000), and is then pruned in close concordance with volumetric refinement in rodents and humans (Van Eden and Uylings, 1985; Giedd et al., 1999). Using mice lacking the Arg nonreceptor tyrosine kinase as a model of adolescent-onset synapse instability (Moresco et al., 2005; Sfakianos et al., 2007), we next investigated the relationship between cortical spine refinement and cocaine-induced behavioral and structural plasticity. Our findings provide the first direct evidence that oPFC spine density — particularly in the context of neocortical maturation - impacts cocaine vulnerability and support an emerging model in which cocaine-induced structural plasticity has behaviorally "protective" consequences (Toda et al., 2006; Pulipparacharuvil et al., 2008; Gourley et al., 2011). Arg is activated by integrin receptor engagement with the extracellular matrix (Bradley and Koleske, 2009); given that integrin-mediated signaling events are impacted by cocaine exposure in mice (Wiggins et al., 2009) and implicated in cocaine addiction in humans (Mash et al., 2007; Drgon et al., 2010), better understanding the role of the downstream Arg kinase may suggest novel pharmacotherapeutic approaches to treating stimulant addiction, particularly in vulnerable populations.

\section{Materials and Methods}

Subjects. arg and $a b l$ knock-out ( $\left.\mathrm{arg}^{-1-} ; \mathrm{abl}^{-1-}\right)$ (Koleske et al., 1998), p190rhogap ${ }^{+1-}\left(p_{190^{+/-}}\right)$(Brouns et al., 2001), and wild-type (wt) littermate mice maintained on a mixed $129 \mathrm{~Sv} / \mathrm{J} \times \mathrm{C} 57 \mathrm{BL} / 6$ background were used at the ages indicated, with the exception of local infusion experiments, which were conducted in C57BL/6 mice from Charles River Laboratories at 8-10 weeks of age. For dendritic spine sampling, $\arg ^{+/-}$ breeders were crossed with mice expressing thy1-derived GFP (Feng et al., 2000) to generate GFP-expressing offspring. All animals were maintained on a $12 \mathrm{~h}$ light cycle (7:00 A.M. on) and provided food and water ad libitum except during instrumental conditioning experiments when body weights were maintained at $\sim 93 \%$ of baseline to motivate instrumental responding for food reinforcement. Animals tested in adulthood were exclusively males; experiments conducted before P36 included both males and females. Procedures were approved by the Yale Institutional Animal Care and Use Committee.

Dendritic spine sampling. Littermate transgenic $\mathrm{arg}^{+/+}$and $\mathrm{arg}^{-1-}$ mice expressing GFP were killed by rapid decapitation for dendritic spine analysis at P21, P24, P31, and P56-P60 or $24 \mathrm{~h}$ after injection in the case of cocaine exposure. We used methods similar to those previously described by our group (Sfakianos et al., 2007): Briefly, fresh brains were submerged in $4 \%$ paraformaldehyde for $48 \mathrm{~h}$, and then transferred to $30 \% \mathrm{w} / \mathrm{v}$ sucrose, followed by slicing into $40-\mu \mathrm{m}$-thick sections on a microtome held at $-15^{\circ} \mathrm{C}$. Slices were mounted, and dendritic segments running parallel to the coronal surface of the section and not overlapping with other segments that would obscure dendritic spine visualization were imaged on a laser-scanning confocal microscope (Olympus Fluoview FV1000) using a $100 \times$ objective with a digital zoom of 3 and laser excitation wavelength at $488 \mathrm{~nm}$. $Z$-steps of $0.5 \mu \mathrm{m}$ were used to generate stacks that included $\sim 1 \mu \mathrm{m}$ above and below the targeted dendritic segment. A Kalman filter reduced background interference. After imaging, the area was photobleached to allow for post hoc confirmation that the image was collected from the lateral oPFC or rostral hippocampal (CA1 apical branches) subregions. Both hemispheres were sampled.

Collapsed $z$-stacks were analyzed using NIH ImageJ: Each protrusion $\leq 4 \mu \mathrm{m}$ was considered a spine (Peters and Kaiserman-Abramof, 1970) and counted. Additionally, spine lengths and head widths (at the widest point) were measured. If a spine bifurcated, only the longest arm was measured and counted. Individual planes were also evaluated to detect protrusions extending perpendicular to the collapsed $z$-stack. Total spine number for each segment was normalized to the length of the dendritic segment to generate density values. Spine-devoid dendritic segments (e.g., those immediately extending from the soma) were not counted, and all scoring was conducted by a single blinded rater.
In the oPFC, eight segments within $150 \mu \mathrm{m}$ of the soma from each of three to four mice per group, depending on litter composition, were scored; a total of 436-590 $\mu \mathrm{m}$ of dendritic material per time point per genotype were scored. Due to the relatively stellate appearance of oPFC neurons, apical versus basal branches were not distinguished (for direct comparison with medial PFC neurons, see Liston et al., 2006; Kolb et al., 2008). Densities were compared by two-factor ANOVA with genotype and age as factors and $n$ constituting branch number. Spine lengths and head widths were compared by the Kolmogorov-Smirnov test.

In the hippocampus, the unique alignment of CA1 neurons allows for clear and unambiguous spine sampling as a function of distance from the somatic layer. Thus, in each $50 \mu \mathrm{m}$ window collected from rostral CA1, starting at the soma, three to four clearly enumerable apical branches were identified and sampled. This approach resulted in 92-204 $\mu \mathrm{m}$ of dendritic material per $50 \mu \mathrm{m}$ sampling window per time point per genotype scored. Protrusion density at each time point was analyzed by twofactor (distance by genotype) ANOVA, and an overall assessment of density was generated by two-factor (genotype by time point) ANOVA with density values collapsed across the entire dendritic length. Values that fell $>2$ SDs outside of the mean were excluded.

As is common practice, each animal in our cellular morphology experiments contributed multiple dendritic segments that were then treated as independent samples when spine densities were analyzed. Normality tests were conducted to confirm that density differences could not be attributed to values from any single individual animal.

Psychostimulant administration. We used a within-subjects repeated low-dose cocaine or methylphenidate (MPH) administration protocol as previously described (Gourley et al., 2009): Animals were injected with either cocaine hydrochloride $(10 \mathrm{mg} / \mathrm{kg}$, i.p.; $1 \mathrm{ml} / 100 \mathrm{~g}$; generously provided by NIDA) or MPH ( $5 \mathrm{mg} / \mathrm{kg}$, i.p.; $1 \mathrm{ml} / 100$ g; Sigma-Aldrich) for 5 consecutive days after $1 \mathrm{~h}$ habituation to a large, clean cage $(41 \times$ $20 \times 20 \mathrm{~cm}$ ). Locomotor activity was monitored with the Omnitech Digiscan Micromonitor system equipped with 16 photocells. Photobeams broken in the $30 \mathrm{~min}$ after injection were normalized to those broken in the $30 \mathrm{~min}$ before injection to control for individual differences in basal activity levels. Normalized photobeam counts on days 1 and 5 were analyzed by repeated-measures ANOVA with day and genotype or infusion as factors. Mice were first injected at one of three ages: P24, P31, or 8-10 weeks of age as indicated. Photobeam breaks generated by repeated interruption of the same photobeam—suggestive of repetitive, stereotyped actions-are reported throughout.

We also tested for the persistence of cocaine or MPH sensitization in adult mice with a "challenge" injection administered after 7-10 drug-free days, also as previously described (Gourley et al., 2009). Here, each animal was monitored for $2.5 \mathrm{~h}$ : First, mice were allowed to habituate to the chamber for $1 \mathrm{~h}$. Mice then received a saline injection and were monitored for $1 \mathrm{~h}$. A second injection containing $10 \mathrm{mg} / \mathrm{kg}$ cocaine or $5 \mathrm{mg} / \mathrm{kg}$ $\mathrm{MPH}$ followed, and photobeam counts during the subsequent $30 \mathrm{~min}$ were counted. Photobeams broken during the 30 min after psychostimulant injection were normalized to those generated during the $30 \mathrm{~min}$ after saline injection to identify the degree to which cocaine or MPH potentiated locomotor activity beyond any conditioned response to injection. Percentage-of-saline values were analyzed by one-factor (genotype) ANOVA for cocaine comparisons and $t$ test for MPH comparisons.

Ifenprodil administration. In a separate group of P31 mice, ifenprodil $(10 \mathrm{mg} / \mathrm{kg}$, i.p., in $5 \% \mathrm{EtOH}$ and saline; Tocris) or vehicle was administered $30 \mathrm{~min}$ before cocaine $(10 \mathrm{mg} / \mathrm{kg}$, i.p.) or saline for 5 consecutive days. The dose and inject-to-test interval were selected based on pilot studies and previous work in adult rats (Schumann and Yaka, 2009). When mice were 9-week-old adults, sensitivity to cocaine "challenge" was assessed: As above, mice were monitored for $1 \mathrm{~h}$ during habituation to the locomotor chamber, for $1 \mathrm{~h}$ following saline injection, and for 30 min following cocaine $(10 \mathrm{mg} / \mathrm{kg}$, i.p.) injection. Again, photobeams broken during the $30 \mathrm{~min}$ after cocaine injection were normalized to those generated during the $30 \mathrm{~min}$ after saline injection.

Instrumental conditioning. Adult mice were used in all instrumental conditioning studies that used methods similar to those previously described (Gourley et al., 2008): Mice were trained to nose poke for food 
reinforcement (20 mg grain pellets; Bio-Serv) in standard MED Associates conditioning chambers equipped with three nose poke recesses. Mice were first exposed to the chambers for $15 \mathrm{~min}$, during which pellets were provided in the food magazine upon each head entry. Nose poke training was then initiated with $1 \mathrm{~h}$ training sessions during which mice were reinforced for entering the nose into a single designated recess one, two, or three times, as randomly determined by the operating computer (i.e., a variable ratio 2 schedule of reinforcement). Initially, reinforcer delivery was uncued; in subsequent experiments as indicated, a 2 s $2 \mathrm{kHz}$ tone coterminated with reinforcer delivery. When responding was stable-defined as the SD of responses made on the active aperture for 3 consecutive days falling $<12 \%$ of the mean number of responses made over the same period-mice proceeded to the next phase of the experiment, instrumental reversal test or instrumental responding for conditioned stimuli. In the case of intracranial microinfusion, infusions were made after instrumental training with drug groups designated by matching animals' response rates on the active aperture.

Instrumental reversal test. In an instrumental reversal task sensitive to oPFC lesions (Gourley et al., 2010) and chronic cocaine exposure (Krueger et al., 2009), the location of the reinforced aperture within the chamber was "reversed," such that a mouse trained to respond on the leftmost aperture was reinforced for responding on the rightmost aperture and vice versa. The center aperture remained un-reinforced. Test sessions were $30 \mathrm{~min}$ in duration and conducted daily for 4 consecutive days. Reponses made on the active and inactive apertures were analyzed by one-factor (genotype or infusion) ANOVA with repeated measures.

Instrumental responding for conditioned stimuli. In mice trained to respond at stable levels for food reinforcers accompanied by an auditory cue, food reinforcement was withheld such that nose poke responding resulted in only tone presentation. Mice were also fully sated. Five such 15 min test sessions were conducted in a single day, and responses made on the active aperture were analyzed by one-factor (genotype or infusion) ANOVA with repeated measures. Responses made for food plus tone during the final $15 \mathrm{~min}$ of training are shown for comparison. One animal routinely responded $>2$ SDs outside of the mean and was excluded.

Local oPFC infusions. For local infusions, mice were anesthetized with ketamine/xylazine. The head was shaved and placed in a stereotaxic frame (David Kopf Instruments). The scalp was incised, skin retracted, bregma and lambda identified, the head leveled, and coordinates located using Kopf's digital coordinate system with resolution of $1 / 100 \mathrm{~mm}$. Two burr holes were drilled, and sterile saline, latrunculin A ( $5 \mu \mathrm{g} / \mu \mathrm{l}$; Sigma-Aldrich), or the Abl family kinase inhibitor 4-[(4-methylpiperazin-1-yl)methyl]- $N$-(4-methyl3-\{[4-(pyridin-3-yl)pyrimidin-2-yl]amino\}phenyl)benzamide (STI-571) (10 mu in saline; kindly provided by Dr. Bill Bornmann, University of Texas, Houston, TX) was infused over $2 \mathrm{~min}$ in a volume of $0.15 \mu \mathrm{l}$ at $+2.6 \mathrm{AP}$, +1.2 ML, -2.8 DV (Bissonette et al., 2008; Gourley et al., 2010). Needles were left in place for 2 additional minutes before withdrawal. Mice were sutured and allowed to recover for $3 \mathrm{~d}$, or $14 \mathrm{~d}$ in the case of delayed testing, at which point experiments resumed. In two mice that did not acquire the instrumental conditioning task, $1 \%$ thionin was infused in the same volume. These brains were extracted, fixed in $4 \%$ paraformaldehyde, sliced into 40 $\mu \mathrm{m}$-thick sections on a microtome held at $-15^{\circ} \mathrm{C}$, mounted, and imaged using a light microscope to illustrate infusion sites. Otherwise, termination of needle tracks in the oPFC was visually confirmed at the conclusion of the experiments.

Statistical analyses. Two-tailed parametric statistical analyses with $\alpha=$ 0.05 were performed using SigmaStat, version 3.1. Tukey's post hoc tests were used in the event of significant ANOVA interaction or main effects, as appropriate. A value of $p \leq 0.05$ indicated a significant difference between groups. Kolmogorov-Smirnov analyses were conducted using MATLAB; due to substantial power generated by large sample sizes, only $p \leq 0.001$ was considered significant. Dendritic spine densities measured as a function of developmental stage were analyzed by two-factor ANOVA but fit to third-order polynomial curves for illustrative purposes; for discussion of curve-fit models, see Payne et al. (2010).

\section{Results}

Arg kinase regulates postnatal dendritic spine maturation

Layer V oPFC dendritic spines, defined as protrusions extending $\leq 4 \mu \mathrm{m}$ from the dendritic shaft (Peters and KaisermanAbramof, 1970), were identified and quantified in transgenic mice expressing thy1-derived GFP (Feng et al., 2000). Lateral oPFC spine density was evaluated at P21, P24, P31, and P56-P60, corresponding to weanling, preadolescence, adolescence, and young adulthood in mice (Spear, 2000). At P21, P24, and P31 in control wt animals, densities were on average $>1$ spine/ $\mu \mathrm{m}$ and peaked at P31, with an average density of 1.32 spines $/ \mu \mathrm{m}$ (main effect, $F_{(3,185)}=3.8 ; p=0.01$; relative to younger ages, $p \leq 0.02$ ). Between P31 and P56-P60, spine density declined to $\sim 1.08$ spines $/ \mu \mathrm{m}$, representing the reduction of $\sim 18 \%$ of spines between P31 and P56-P60 ( $p=0.02$ ) (Fig. 1a,b). Interestingly, spine densities in mice lacking the cytoskeletal regulator Arg kinase were indistinguishable from control levels at P21 and P24 ( $p \geq 0.5$ ), but densities dropped-rather than peaked-at P31 and remained low into adulthood (time by genotype, $F_{(3,185)}=$ 7.9; $p<0.001$; post hoc values of $p \leq 0.02$ relative to age-matched control), representing a $\sim 19 \%$ reduction of dendritic spines compared with adult wt littermates (Fig. 1a,b).

Dendritic spine densities in adult layer $\mathrm{V}$ oPFC here were comparable with those determined following Lucifer yellow or biocytin loading (Liu and Aghajanian, 2008; Chen et al., 2009; Li et al., 2010), or by electron microscopy (Kuroda et al., 1996) of adult proximal layer $\mathrm{V}$ dendrites in the adjacent prelimbic cortex. Spine densities were slightly higher than those reported following analyses of Golgi-impregnated layer II/III oPFC $[\sim 0.86 / \mu \mathrm{m}$ in the study by Kolb et al. (2004)] (but see Muhammad and Kolb, 2011a,b) and Golgi-impregnated deep-layer prelimbic cortex (Sherren and Pappas, 2005; Wang and Deutch, 2008; Ball et al., 2009; Andolina et al., 2011). Larger values may reflect greater sensitivity of fluorescence techniques in detecting smaller spines (Shen et al., 2009), but direct comparisons with Golgi-Coximpregnated layer V oPFC are limited because Golgi impregnation largely spares layer V oPFC neurons (Kolb et al., 2008).

We also analyzed dendritic spines in a region not expected to show late-stage dendritic spine refinement-hippocampal CA1. On rostral CA1 apical dendrites, spine pruning was indeed not evident between P31 and P56-P60; instead, a persistent incremental elevation in spine density from P21 to adulthood was identified in control wt mice, with highest densities at P56-P60 (main effect of age, $F_{(3,593)}=3.6 ; p=0.01$; post hoc values of $p \leq$ 0.02 ) (Fig. 1c), as predicted based on electron microscopy studies (Harris et al., 1992). As in the oPFC, Arg deficiency resulted in a decline in density that was first detectable at $\mathrm{P} 31$, and persisted to P56-P60 (interaction, $F_{(3,593)}=8.1 ; p<0.001$; post hoc values of $p<0.001$ relative to age-matched control).

We next evaluated spine density in rostral CA1 as a function of distance from the somatic layer. This approach indicated density was reduced throughout the dendritic arbor at P31 (main effect of genotype, $F_{(1,131)}=16.3 ; p<0.001$ ) (Fig. $\left.1 d_{3}, f\right)$. By P56-P60, however, reductions in spine density were primarily concentrated to a highly branched region 200-350 $\mu \mathrm{m}$ from the cell body layer targeted by the Schaffer collaterals (Amaral and Lavenex, 2007) (distance by genotype interaction, $F_{(7,132)}=3.2$; $p=0.004$; post hoc values of $p \leq 0.004$ ) (Fig. $1 d_{4}, f$ ). As expected, analyses at P21 and P24 did not reveal genotypic differences (Fig. $\left.1 d_{1}, d_{2}, f\right)$.

Spine lengths at P31 and P56-P60 were also analyzed to evaluate the gross morphology of individual spines at critical time 

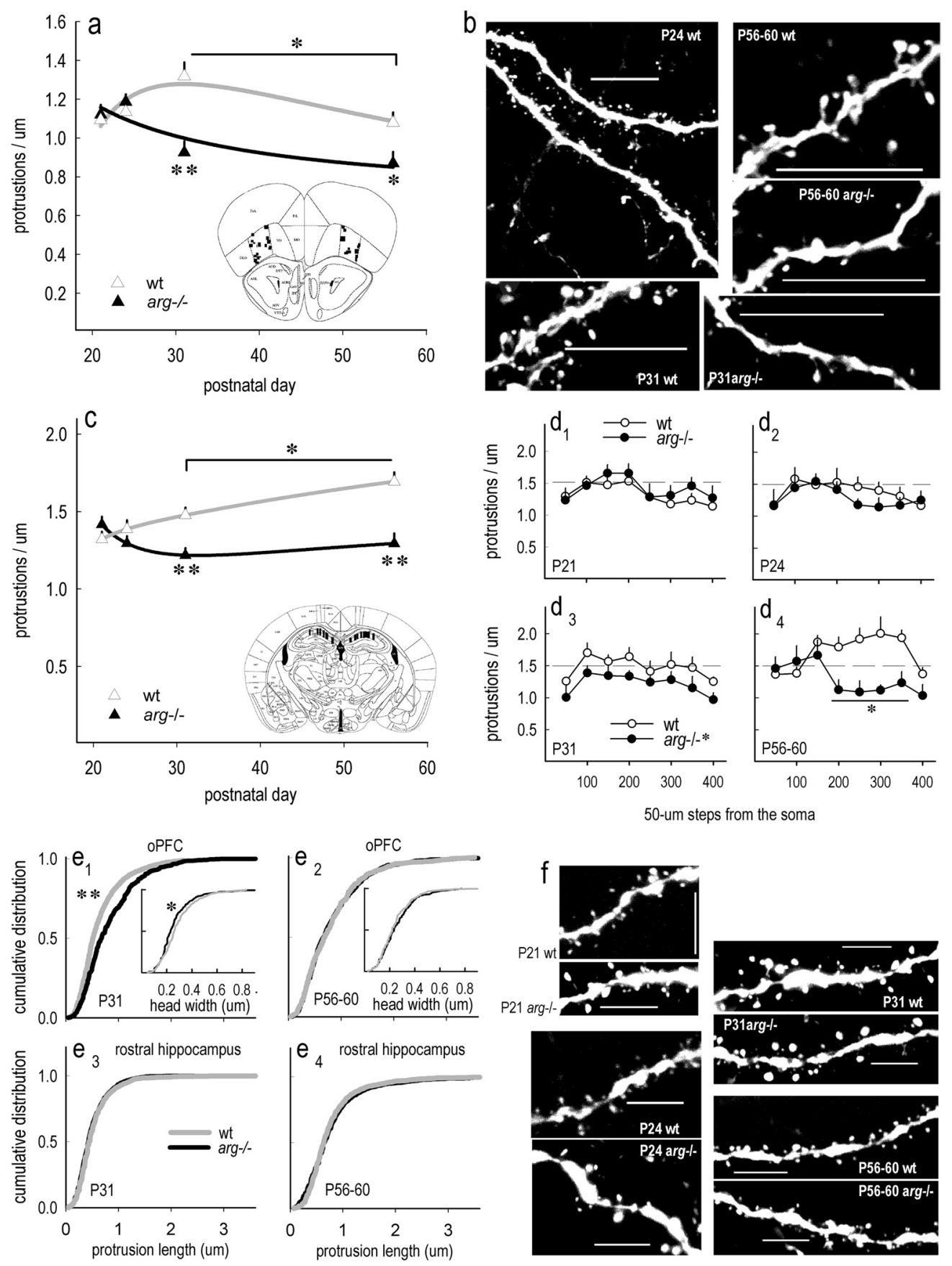

Figure 1. Arg deficiency redirects postnatal dendritic spine refinement. $\boldsymbol{a}$, Dendritic spines were enumerated in layer V oPFC at P21, P24, P31, and P56-P60. Spine density peaked at P31 and then declined as control animals entered adulthood. In arg $^{-1-}$ mice, however, spine density dropped precipitously at P31 and remained low. Densities did not differ between arg ${ }^{-1-}$ and wild-type cells at P21 and P24. Inset, Plate from Franklin and Paxinos (2007) at bregma 2.58 with oPFC sampling sites represented by black boxes. $\boldsymbol{b}$, Representative oPFC dendrites with ages and genotypes indicated. Scale bars, $10 \mu \mathrm{m}$. c, In rostral CA1, wild-type spine density increased across postnatal development, but again, densities in $\arg ^{-1-}$ mice diverged at P31 and remained low at P56-P60. Inset, Plate at bregma - 1.7 with black boxes representing sampling sites. $\boldsymbol{d}$, Hippocampal spine density was analyzed as a function of distance from the somatic layer, revealing nonselective loss at P31. By P56-P60, loss was concentrated to a region 200 -350 $\mu \mathrm{m}$ from the cell body layer. A dashed linewas placed at 1.5 to facilitate comparison between plots.e, Dendriticspine lengths were also measured at P31 (adolescence) and P56 -P60 (early adulthood). Cortical spines in adolescent $\mathrm{arg}^{-1-}$ mice were longer than control spines at the same age, suggestive of an immature phenotype; consistent with this interpretation, spine head widths were also smaller in adolescent arg $^{-1-}$ mice (inset). These phenotypes appeared transient, however, since differences were not detected at P56-P60 (or P21 and P24) (data not shown). Hippocampal spine lengths did not differ between genotypes at any time point. $\boldsymbol{f}$, Representative hippocampal dendrites with ages and genotypes indicated. Scale bars, $5 \mu \mathrm{m}$. Symbols represent means + SEMs. ${ }^{*} p<0.05 ;{ }^{* *} p<0.0001$.

points. Arg deficiency resulted in longer cortical spines at P31 (Kolmogorov-Smirnov, $p<0.0001$ ) (Fig. $1 e_{1}$ ), suggestive of an immature spine phenotype (for review, see Bhatt et al., 2009). Smaller head widths supported this impression (KolmogorovSmirnov, $p=0.001)$ (Fig. $1 e_{1}$, inset), but both effects were undetectable at P56-P60 (Fig. 1 $e_{2}$ ), and thus likely transient. Spine lengths did not differ in the hippocampus (Fig. $1 e_{3}, e_{4}$ ).
The developmental trajectory of oPFC spine refinement predicts cocaine vulnerability

We hypothesized that reduced oPFC dendritic spine density may confer vulnerability to cocaine exposure. According to this hypothesis, $\mathrm{arg}^{-1-}$ mice should exhibit exaggerated psychomotor sensitivity to cocaine at $\mathrm{P} 31$ when reductions in spine density are first detectable. Indeed, $\mathrm{arg}^{-1-}$ mice administered cocaine from 
P31 to P35 showed exaggerated locomotion in response to repeated cocaine injection (main effect, $F_{(1,8)}=6 ; p=0.04$ ) (Fig. 2a). When tested from P24 to P28 before reductions in spine density are identified, $\mathrm{arg}^{-1-}$ mice did not differ from control mice $(F<1)$, providing compelling evidence that reductions in oPFC dendritic spine density correlate closely with cocaine-mediated behavioral plasticity. In both cases, sensitivity to cocaine increased with repeated exposure, reflecting classical sensitization effects (values of $p<0.001$ ).

Based on these findings, pharmacological compounds that grow and stabilize cortical synapses and spines might be predicted to protect adolescent animals from the long-term effects of cocaine. Because glutamate signaling through NR2Acontaining NMDA receptors during postnatal development indeed stabilizes adolescent synapses during critical periods and in response to environmental stimuli (see Discussion), mice of both genotypes were administered the NR2Bselective NMDA receptor antagonist ifenprodil before cocaine from P31 to P35. When locomotor sensitivity to cocaine was tested in adulthood at 9 weeks of age, mice exposed to cocaine starting at P31 without ifenprodil pretreatment generated more photobeam breaks than untreated mice (main effect, $F_{(2,53)}=9.9 ; p<$ 0.001 ; post hoc $p=0.001$ ) (Fig. $2 b$ ), reflecting classical sensitization effects_- persistent hyperreactivity to drug exposure despite prolonged abstinence (for review, see Pierce and Kalivas, 1997). As in our previous studies, $\arg ^{-1-}$ mice showed greater sensitivity that littermate wt mice (main effect of arg genotype, $\left.F_{(1,53)}=7 ; p=0.01\right)$. Most notably, however, adolescent ifenprodil treatment normalized the locomotor response to cocaine to baseline (vs cocaine alone, $p<0.04$ ), such that the locomotor response in ifenprodil-treated mice did not differ from mice administered only saline in adolescence $(p=0.3)$. In other words, adolescent ifenprodil blocked adolescent-onset cocaine sensitization.

\section{Cocaine-induced structural reorganization requires Arg and brakes psychostimulant sensitization}

Current evidence indicates that amphetamine-like psychostimulants atrophy oPFC dendritic spines (see Introduction). To evaluate whether Arg kinase plays a role in this process, we again exposed mice to cocaine from P31 to P35, administered a "challenge" injection at 9 weeks of age, and then fixed and imaged oPFC dendritic spines $24 \mathrm{~h}$ after the final injection. Cocaine exposure decreased dendritic spine density in wt mice as expected (genotype by cocaine, $F_{(1,99)}=5.8 ; p=0.02$; post hoc $\left.p=0.005\right)$. Cocaine-naive $\arg ^{-1-}$ spine density was reduced relative to wt also as expected $(p<0.001)$, but densities were not further suppressed by cocaine $(p=0.53)$ (Fig. $2 c)$. As has been reported in the nucleus accumbens (Shen et al., 2009), cocaine increased oPFC spine head size in wt animals (Kolmogorov-Smir-
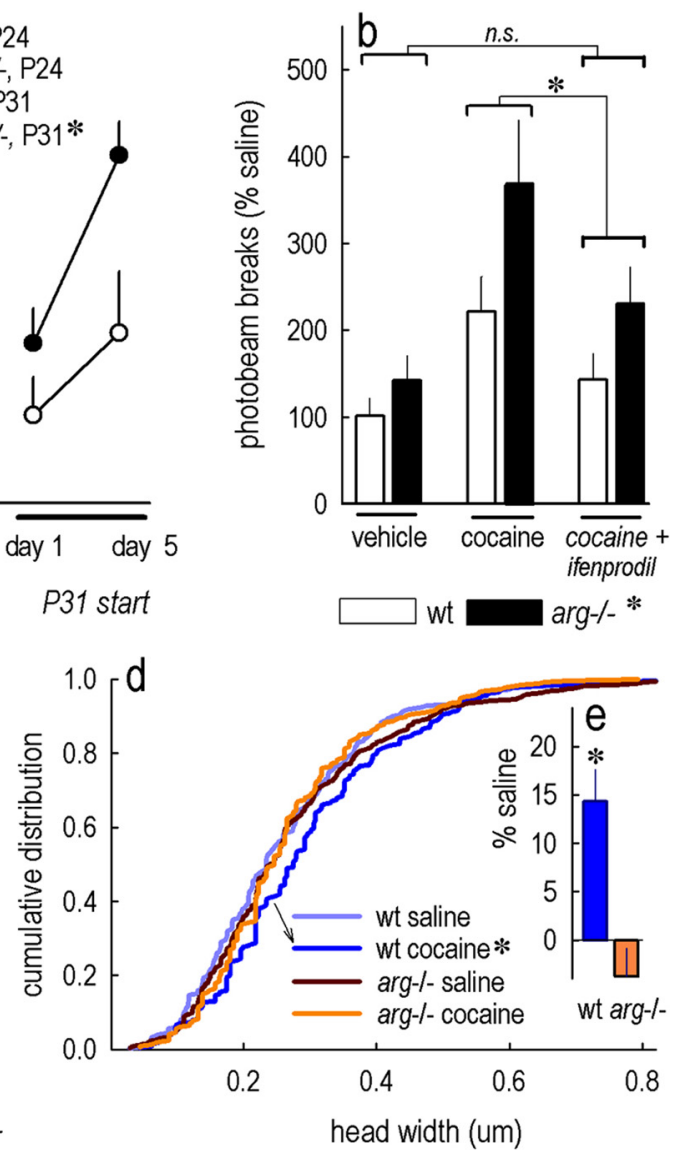

Figure 2. Arg regulates the psychomotor and cytoskeletal response to cocaine. $\boldsymbol{a}$, The locomotor response to repeated cocaine exposure in wild-type and arg $^{-1-}$ mice did not differ when cocaine was administered from P24 to P28, before arg $^{-1-}$ spine loss. to to an acute cocaine challenge as 9-week-old adults. Ifenprodil pretreatment blocked sensitization. $c$, The morphological response (o but again, arg $^{-1-}$ spines did not respond to cocaine. e, Overall, wild-type oPFC spine heads were nearly $15 \%$ wider after cocaine; $\arg ^{-1-}$ spines did not change. Symbols and bars represent means + SEMs. ${ }^{*} p<0.05$ as indicated.

nov, $p<0.0001)$, but again, $\arg ^{-1-}$ spines were not affected $(p=0.63)$ (Fig. 2d).

Overall, wt spines showed a nearly $15 \%$ increase in head width in response to cocaine, while $\arg ^{-1-}$ spines hovered at $\sim 0 \%$ change $(t=-4.0 ; p<0.001)$ (Fig. $2 e)$. These data suggest that the structural response to cocaine may impact psychomotor sensitivity. To test this possibility, the neurotoxin latrunculin $\mathrm{A}$, which blocks actin polymerization, was infused into the lateral oPFC before cocaine injection in adult wt mice. Acute infusion increased cocaine-elicited photobeam breaks relative to salineinfused control groups (main effect, $F_{(3,33)}=10.7 ; p<0.001$; post hoc values of $p<0.05$ ) (Fig. 3a). Microinfusion of the Abl family kinase inhibitor STI-571 also potentiated psychomotor sensitivity to cocaine (day by drug interaction, $F_{(3,33)}=3.6 ; p=0.02$ ), particularly after repeated cocaine injection (day $5, p=0.004$ ) (Fig. 3a).

We also confirmed that reduced gene dosage of the Arg substrate p190RhoGAP potentiated cocaine-elicited locomotor activity to a comparable degree as arg knock-out (main effect, $F_{(3,37)}=9.8 ; p<0.001$; post hoc vs wt, both $p<0.02$ ) (Fig. $3 b)$. By contrast, mice deficient in the closely related Abl kinase were not differentially affected $(p=0.65)$ (Fig. $3 b)$, sug- 

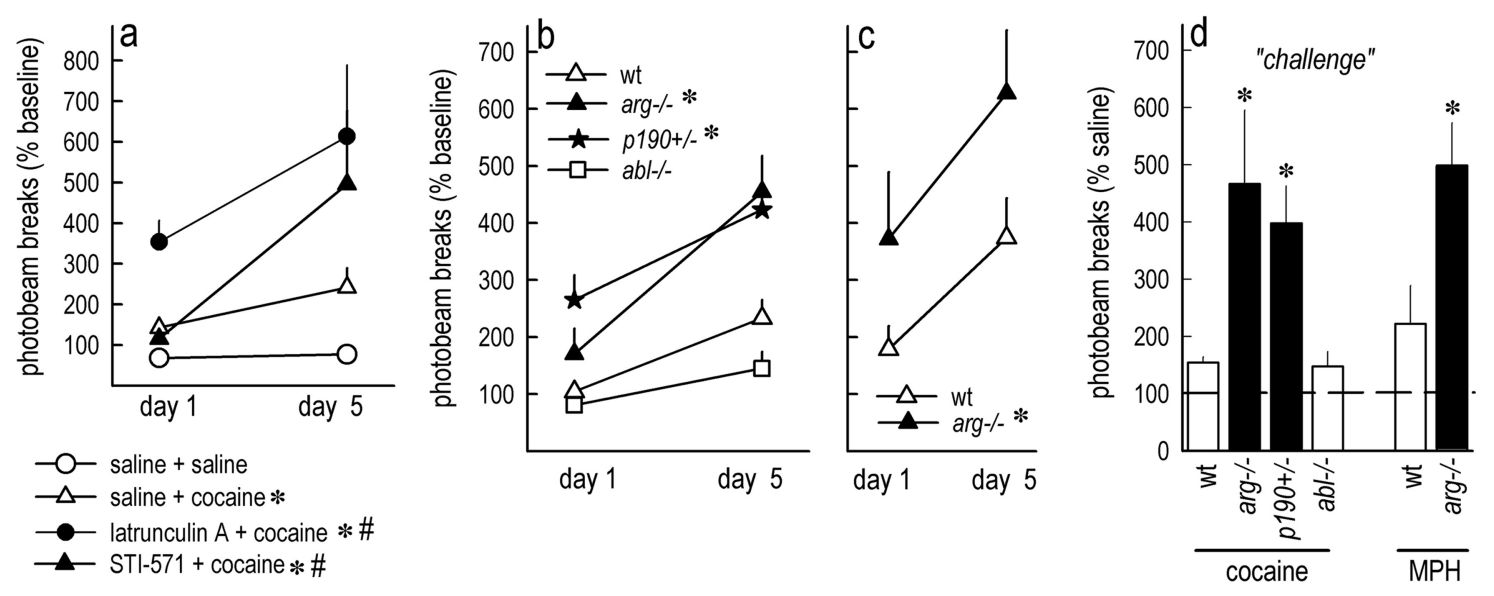

Figure 3. Potentiation of psychostimulant sensitivity by targeted latrunculin A, Abl family kinase inhibition, and p190RhoGAP knockdown. $\boldsymbol{a}$, Mice were infused into the oPFC with latrunculin A or the Abl family kinase inhibitor STI-571. Both compounds potentiated the locomotor response to five subsequent daily cocaine injections. ${ }^{*} p<0.05$ relative to intracranial saline plus systemic saline; ${ }^{*} p<0.05$ relative to intracranial saline plus systemic cocaine. $\boldsymbol{b}$, p190RhoGAP-deficient mice $\left(p 190^{+/-}\right.$) also showed heightened locomotor sensitivity on par with arg ${ }^{-/-}$mice, while $a b^{-I-}$ mice did not differ from littermate wild-type mice. ${ }^{*} p<0.05$ versus wild type. $c$, The locomotor response to repeated MPH exposure was also exaggerated in arg ${ }^{-1-}$ mice at a dose

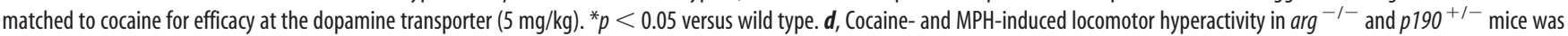
persistent, as indicated by increased activity relative to littermate wild-type control mice after a "challenge" injection administered after 7-10 d drug-free. The dashed line at $100 \%$ represents the locomotor response to saline. ${ }^{*} p<0.05$ versus wild type. The bars and symbols represent group means + SEMs.

gesting the effects of the Abl family kinase inhibitor STI-571 were attributable to inhibiting Arg, and not Abl, kinase.

Behavioral effects in $\mathrm{arg}^{-1-}$ mice did not appear to be specific to cocaine, as Arg deficiency potentiated the locomotor response to repeated $\mathrm{MPH}$ exposure (main effect, $F_{(1,13)}=6.7 ; p=0.02$ ) (Fig. $3 c$ ). Sensitivity to both cocaine and MPH remained elevated in $\mathrm{arg}^{-1-}$ and $\mathrm{p}^{-190^{+-}}$mice despite a $7-10 \mathrm{~d}$ drug-free period modeling abstinence in humans (for cocaine, $F_{(3,38)}=7.3 ; p<$ 0.001 , post hoc values of $p<0.04$; for $\mathrm{MPH}, t=-3, p=0.01$ ) (Fig. 3d).

\section{Arg regulates $\mathrm{oPFC}$-dependent decision making}

We next evaluated whether the disruption of Arg kinase signaling impacts oPFC-dependent decision making in tasks used to model certain aspects of drug addiction. As previously reported (Gourley et al., 2009), Arg deficiency did not impair response acquisition during initial training (data not shown), but upon reversal of the instrumental response requirement, $\mathrm{arg}^{-l-}$ mice were impaired in both acquiring a new response to obtain food reinforcement (main effect, $F_{(1,14)}=7.6 ; p<0.05$ ) and in suppressing "perseverative" responding-responding on a previously reinforced aperture that is no longer active (main effect, $F_{(1,14)}=6.4 ; p=0.02$ ) (Fig. $4 a$ ). Wild-type mice with local oPFC Arg kinase blockade also failed to acquire a new response (main effect, $F_{(1,14)}=5.6 ; p=0.03$ ), and infusions had no effects on perseverative responding $(F<1)$ (Fig. $4 b)$, thus mimicking the effects of selective excitotoxic lesions of the lateral oPFC (Gourley et al., 2010). Our infusion protocol was selected based on previously published protocols in which NMDA spread was limited to the ventral and lateral oPFC compartments (Bissonette et al., 2008; Gourley et al., 2010), and histological analyses confirmed that infusion sites were restricted to the lateral oPFC compartment (Fig. 4, inset). Drug diffusion could not be measured in the present experiments, however, so it should be noted that we cannot conclusively argue that the medial oPFC was unaffected.

Response acquisition deficits may be attributable to an inability to modify response strategies in the presence of rewardassociated conditioned stimuli (for discussion, see Ostlund et al., 2010). Thus, we trained mice to respond for food reinforcers accompanied by an auditory tone signaling food delivery. When food, but not the tone, was withheld, sated $\mathrm{arg}^{-1-}$ mice continued to respond at $100 \%$ of baseline, while response rates in wt mice dropped (main effect, $F_{(1,11)}=5 ; p=0.05$ ) (sum; Fig. $4 c$ ). STI-571 infusions had comparable effects, with STI-571-infused mice generating more responses for the conditioned stimulus than saline controls (main effect, $F_{(1,14)}=6.1 ; p=0.03$ ) (Fig. $4 d$ ), indicating that $\mathrm{Arg}$ kinase inhibition impairs the ability to modify behavioral strategies in response to reward-related cues. A separate group of mice was tested after a 2 week STI-571 washout period; in this case, no effects of STI-571 exposure were identified $(F<1)$ (Fig. $4 e$ ).

\section{Discussion}

Dendritic spines are the postsynaptic components of most excitatory synapses in the mammalian brain. Spines are remarkably plastic, particularly during adolescence, which is characterized by marked neocortical synaptogenesis and spinogenesis, then substantial structural pruning and refinement (Bourgeois et al., 1994; Rakic et al., 1994; Anderson et al., 1995; Bhatt et al., 2009). These processes are hypothesized to optimize decision-making capacity (Spear, 2000), while disruption by environmental and/or genetic influences may confer vulnerability to typically adolescent-onset psychiatric disorders including drug addiction and schizophrenia (Lewis, 1997; Chambers et al., 2003; Garey, 2010). Here, we build on evidence that deletion of the integrin-activated Arg kinase derails dopamine receptor refinement in the adolescent PFC (Gourley et al., 2009) and show that a subset of spines in Arg-deficient oPFC collapse in early adolescence in concert with the emergence of psychomotor hypersensitivity to cocaine. Both $\arg$ deletion and targeted inhibition of Arg kinase activity fundamentally impair oPFC-dependent decision-making processes, and at a structural level, $\mathrm{arg}^{-1-}$ dendritic spines fail to respond to cocaine. Latrunculin A infusions and reduced gene-dosage of p190RhoGAP also exaggerate psychomotor sensitivity, providing considerable support for the growing perspective that the cytoskeletal response to cocaine and other amphetamine-like psychostimulants has "protective" consequences. Especially given evidence of modified in- 
tegrin signaling in cocaine-addicted populations (Mash et al., 2007; Drgon et al., 2010) and cocaine-exposed animals (Wiggins et al., 2009), further insight could advance addiction treatment, particularly in developmentally vulnerable populations.

\section{Prefrontal structural refinement in adolescence is Arg dependent}

Adolescence represents a window of substantial cortical plasticity and activitydependent synaptic refinement. For example, in the oPFC, weaning time and early life social experience have complex interactive consequences for dendritic complexity in adulthood (Bock et al., 2008). In the barrel cortex, sensory deprivation, which denies neurons of critical activity-dependent neuroplasticity, slows adolescent spine pruning and ultimately results in a net loss of dendritic spines (Zuo et al., 2005). A shallow spine elimination curve and net loss also characterize the adolescent $\mathrm{arg}^{-1-}$ oPFC, and the concentration of hippocampal CA1 spine loss to a region of heavy input from the Schaffer collaterals implicates Arg in neuronal sculpting that is activity dependent, rather than passive. Given that Arg is activated by integrin receptor engagement with the extracellular matrix (Bradley et al., 2006), these effects might be anticipated but had not been previously verified.

In $\mathrm{arg}^{-1-}$ mice, oPFC spine density grows between P21 and P24 but collapses by $\mathrm{P} 31$, likely reflecting permanent cortical synapse loss (Gourley et al., 2009). In concert with the emergence of structural deficiencies, motoric hypersensitivity to cocaine becomes evident at P31, while $\mathrm{arg}^{-1-}$ mice subjected to identical testing before P31 do not differ from wt littermates. This temporal convergence provides empirical support for the widely held hypothesis that structural instability in adolescence contributes to heightened vulnerability to cocaine and other psychostimulants such as methylphenidate.

We therefore attempted to block the sensitizing effects of adolescent cocaine exposure by pretreating mice with ifenprodil, an NR2Bselective NMDA antagonist expected to bias cocaine-elicited glutamate signaling through NR2A-containing NMDA receptorsNR2A signaling stabilizes functional synapses during early-life critical periods (Quinlan et al., 1999b; Loftis and Janowsky, 2000) and in response to environmental stimuli (Quinlan et al., 1999a; Yashiro and Philpot, 2008). Like broad-spectrum NMDA antagonists, ifenprodil blocks cocaine sensitization in adult animals (Ujike et al., 1992; Kalivas and Alesdatter, 1993; Schumann and Yaka, 2009). Effects were previously believed to be transient, but we show that adolescent treatment blocks the sensitized response to cocaine persistently, here 4 weeks later. Long-term benefits from adolescent treatment resonate with the long-term consequences of adolescent sensory deprivation on neuronal structure in the barrel cortex, given that the same deprivation protocol has relatively
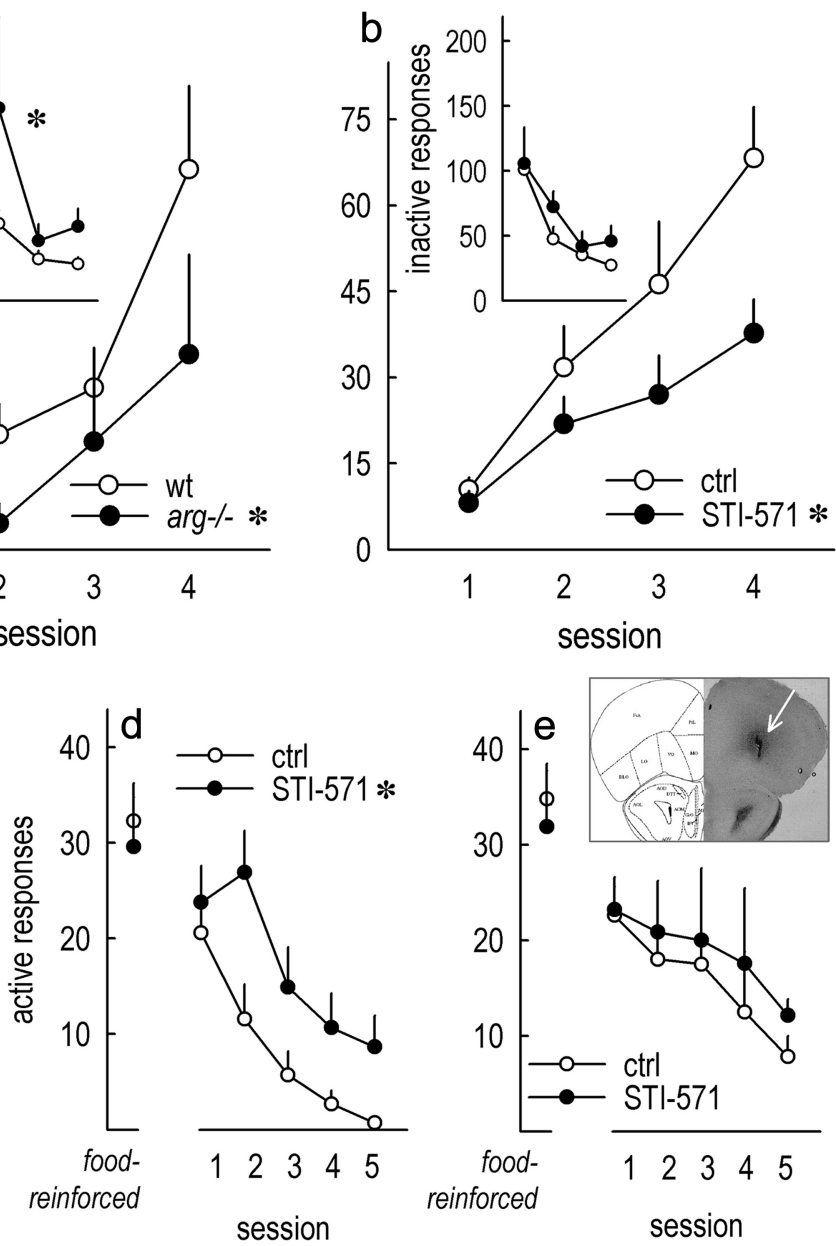

Figure 4. Arg kinase regulates oPFC-dependent decision making. $\boldsymbol{a}, \mathrm{arg}^{-1-}$ mice were impaired in acquiring a new response in an instrumental reversal task. Inset, Responses on the previously reinforced aperture ("inactive" responses) were also exaggerated in arg $^{-1-}$ mice. $\boldsymbol{b}, 0$ PFC STI-571 infusions targeted to the lateral compartment selectively impaired response acquisition. $\boldsymbol{c}$ mice also performed more responses for reward-associated conditioned stimuli (total of 5 test sessions). $\boldsymbol{d}$ OPFC STI-571 infusions also increased responding for cues associated with food reinforcement despite equivalent responding for food before infusion. $\boldsymbol{e}$, Response patterns were unaffected if mice were allowed a 2 week washout period after STI-571 infusion before test. Inset, Representative infusion site at arrow. The symbols represent group means + SEMs. ${ }^{*} p<0.05$.

limited effects when applied in adulthood (Zuo et al., 2005). That $\mathrm{arg}^{-1-}$ mice were sensitive to ifenprodil implies that this compound might be an efficacious treatment approach even in genetically vulnerable adolescent cocaine users.

\section{Arg kinase orchestrates the structural response to cocaine}

Although amphetamine-like psychostimulants are widely acknowledged regulators of cell structure, whether the morphological response to these and other addictive compounds contributes to or "protects against" the development of addiction has been a topic of considerable debate. We report that, like amphetamine (Muhammad and Kolb, 2011a,b), cocaine reduces oPFC spine density, and we also show that repeated cocaine exposure enlarges remaining spine heads, as in the nucleus accumbens (Shen et al., 2009). Arg-deficient neurons fail to respond on both measures, suggesting that the behavioral vulnerabilities to cocaine in arg $^{-1-}$ mice (Figs. 2, 3) (Gourley et al., 2009, 2011) reflect the failure to mount or sustain a structural response to cocaine. oPFC-targeted microinfusions of latrunculin A, which blocks actin polymerization, exaggerate the psychomotor response to cocaine, again echoing previous reports that nucleus accumbens 
latrunculin A infusions potentiate cocaine-primed reinstatement, an animal model of relapse (Toda et al., 2006). Moreover, mice deficient in p190RhoGAP, which stabilizes neuronal structure by inhibiting the RhoA GTPase (Hernández et al., 2004), also show cocaine hypersensitivity. These findings together support an emerging model in which the cytoskeletal response to cocaine may mitigate the behavioral response to subsequent exposure.

Cocaine-induced head enlargement in wt mice might be interpreted as merely a compensatory response to a net reduction in dendritic spines, but previous reports indicate that the electrophysiological response of oPFC neurons to amphetamine predicts amphetamine-induced locomotor activity and its disruptive effects on instrumental behavior (Homayoun and Moghaddam, $2006,2008)$. How synaptic activity and stability in the oPFC contribute to psychomotor sensitization, a process largely attributed to progressive and protracted drug-induced modifications in the downstream neural circuits mediating incentive salience, remains unclear. Developing a more comprehensive view of the intracellular signaling mechanisms that orchestrate the structural response to amphetamine and amphetamine-like psychostimulants within the oPFC - and identifying how that response impacts behavioral outcomes-may provide critical insights into addiction.

\section{Arg regulates oPFC-dependent decision making}

Sensitization to psychostimulants models early aspects of addiction (Vanderschuren and Pierce, 2010), while decision making based on heightened sensitivity to reward-predictive cues likely contributes to both addiction development and persistence (Jentsch and Taylor, 1999). We thus characterized decision-making capacity in $\mathrm{arg}^{-1-}$ mice using an instrumental task that requires animals to modify previously learned instrumental response strategies to acquire food. Arg knock-out and Abl family kinase inhibition in the oPFC impaired response acquisition, recapitulating effects of chronic cocaine exposure (Krueger et al., 2009), and we argue that sustained spine loss may be a common mechanism. Notably, $\mathrm{arg}^{-1-}$ mice, but not oPFC STI-571-infused mice, also failed to inhibit non-reinforced responding, mirroring behavioral deficits after selective medial oPFC lesions (Gourley et al., 2010), and likely reflecting the consequences of Arg deficiency across multiple prefrontal compartments.

Arg knock-out and Abl family kinase inhibition in the oPFC also increased sensitivity to reward-predictive cues even when those cues failed to predict reinforcement, suggesting behavioral deficits may be attributable to a failure to update expected outcomes. Indeed, under normal circumstances, the oPFC fosters stimulus-outcome associative learning (Ostlund and Balleine, 2007), although in previous studies, oPFC lesions reduced sensitivity to reward-predictive stimuli. Nonetheless, we hypothesize that disruption of an amygdala-oPFC circuit can account for disorganized decision making here, since the basolateral amygdala endows oPFC neurons with information regarding expected outcomes, and disconnection of these structures yields resistance to outcome devaluation (Baxter et al., 2000; Schoenbaum et al., 2003). This interpretation is indirectly supported by the loss of deep-layer oPFC dendritic spines in $\mathrm{arg}^{-1-}$ mice, since these neurons are characterized by reciprocal connections with the amygdala (Ottersen, 1982; Bacon et al., 1996; Ghashghaei et al., 2007).

Layer $\mathrm{V}$ neurons were targeted in this investigation because their connectivity with the basal forebrain and nucleus accumbens (Brog et al., 1993; Ghashghaei and Barbas, 2001) implicates them in psychostimulant addiction (Jentsch and Taylor, 1999;
Kalivas and Volkow, 2005; Stalnaker et al., 2009). Dendritic spine loss in more superficial layers - primarily layer III-is thought to contribute to disorganized thought and decision making in schizophrenia (Garey, 2010). Future studies will evaluate the role of Arg kinase in these neurons, particularly since layers I-IV are more dramatically pruned during adolescence than layer $\mathrm{V}$ (Bourgeois et al., 1994).

\section{Conclusions}

Since the seminal work of Robinson and Kolb (1997), the relationship between psychostimulant exposure and dendritic spine structure has been a topic of intense interest. Experiments to this end generally evaluate the effects of sensitizing psychostimulant exposure on striatal or prefrontal dendritic spine morphology, while experiments addressing whether events that impact the actin cytoskeleton trigger behavioral vulnerabilities have been limited. Our efforts in this domain support an emerging model in which the cytoskeletal response to cocaine mitigates the behavioral response to subsequent exposure, particularly during adolescence. Given increasing recognition that even highly heritable psychiatric diseases such as drug addiction, schizophrenia, and autism are unlikely to be caused by specific genetic mutations, determining common signaling cascades in which so-called "risk genes" function is critical (Penzes et al., 2011). Thus, future identification and characterization of specific integrin receptors and their ligands that act through Arg to control neuronal structure and stability during adolescence and/or in response to cocaine may shed more focused light onto signaling cascades that could serve as promising therapeutic targets.

\section{References}

Amaral D, Lavenex P (2007) Hippocampal neuroanatomy. In: The hippocampus book (Anderson P, Morris R, Amaral D, Bliss T, O'Keefe J, eds), pp 27-114. New York: Oxford UP.

Anderson SA, Classey JD, Condé F, Lund JS, Lewis DA (1995) Synchronous development of pyramidal neuron dendritic spines and parvalbuminimmunoreactive chandelier neuron axon terminals in layer III of monkey prefrontal cortex. Neuroscience 67:7-22.

Andolina D, Conversi D, Cabib S, Trabalza A, Ventura R, Puglisi-Allegra S, Pascucci T (2011) 5-Hydroxytryptophan during critical postnatal period improves cognitive performances and promotes dendritic spine maturation in genetic mouse model of phenylketonuria. Int J Neuropsychopharmacol 14:479-489.

Bacon SJ, Headlam AJ, Gabbott PL, Smith AD (1996) Amygdala input to medial prefrontal cortex $(\mathrm{mPFC})$ in the rat: a light and electron microscope study. Brain Res 720:211-219.

Ball KT, Wellman CL, Fortenberry E, Rebec GV (2009) Sensitizing regimens of ( \pm )3,4-methylenedioxymethamphetamine (ecstasy) elicit enduring and differential structural alterations in the brain motive circuit of the rat. Neuroscience 160:264-274.

Baxter MG, Parker A, Lindner CC, Izquierdo AD, Murray EA (2000) Control of response selection by reinforcer value requires interaction of amygdala and orbital prefrontal cortex. J Neurosci 20:4311-4319.

Bhatt DH, Zhang S, Gan WB (2009) Dendritic spine dynamics. Annu Rev Physiol 71:261-282.

Bissonette GB, Martins GJ, Franz TM, Harper ES, Schoenbaum G, Powell EM (2008) Double dissociation of the effects of medial and orbital prefrontal cortical lesions on attentional and affective shifts in mice. J Neurosci 28:11124-11130.

Bock J, Murmu RP, Ferdman N, Leshem M, Braun K (2008) Refinement of dendritic and synaptic networks in the rodent anterior cingulate and orbitofrontal cortex: critical impact of early and late social experience. Dev Neurobiol 68:685-695.

Bourgeois JP, Goldman-Rakic PS, Rakic P (1994) Synaptogenesis in the prefrontal cortex of rhesus monkeys. Cereb Cortex 4:78-96.

Bradley WD, Koleske AJ (2009) Regulation of cell migration and morphogenesis by Abl-family kinases: emerging mechanisms and physiological contexts. J Cell Sci 122:3441-3454. 
Bradley WD, Hernández SE, Settleman J, Koleske AJ (2006) Integrin signaling through Arg activates p190RhoGAP by promoting its binding to p120RasGAP and recruitment to the membrane. Mol Biol Cell 17:4827-4836.

Brog JS, Salyapongse A, Deutch AY, Zahm DS (1993) The patterns of afferent innervation of the core and shell in the "accumbens" part of the rat ventral striatum: immunohistochemical detection of retrogradely transported Fluoro-Gold. J Comp Neurol 338:255-278.

Brouns MR, Matheson SF, Settleman J (2001) p190 RhoGAP is the principal Src substrate in brain and regulates axon outgrowth, guidance and fasciculation. Nat Cell Biol 3:361-367.

Butter CM, Mishkin M, Rosvold HE (1963) Conditioning and extinction of a food-rewarded response after selective ablations of frontal cortex in rhesus monkeys. Exp Neurol 7:65-75.

Chambers RA, Taylor JR, Potenza MN (2003) Developmental neurocircuitry of motivation in adolescence: a critical period of addiction vulnerability. Am J Psychiatry 160:1041-1052.

Chen JR, Yan YT, Wang TJ, Chen LJ, Wang YJ, Tseng GF (2009) Gonadal hormones modulate the dendritic spine densities of primary cortical pyramidal neurons in adult female rat. Cereb Cortex 19:2719-2727.

Crews F, He J, Hodge C (2007) Adolescent cortical development: a critical period of vulnerability for addiction. Pharmacol Biochem Behav $86: 189-199$

Crombag HS, Gorny G, Li Y, Kolb B, Robinson TE (2005) Opposite effects of amphetamine self-administration experience on dendritic spines in the medial and orbital prefrontal cortex. Cereb Cortex 15:341-348.

Drgon T, Zhang PW, Johnson C, Walther D, Hess J, Nino M, Uhl GR (2010) Genome wide association for addiction: replicated results and comparisons of two analytic approaches. PLoS One 5:e8832.

Ersche KD, Roiser JP, Robbins TW, Sahakian BJ (2008) Chronic cocaine but not chronic amphetamine use is associated with perseverative responding in humans. Psychopharmacology 197:421-431.

Feng G, Mellor RH, Bernstein M, Keller-Peck C, Nguyen QT, Wallace M, Nerbonne JM, Lichtman JW, Sanes JR (2000) Imaging neuronal subsets in transgenic mice expressing multiple spectral variants of GFP. Neuron 28:41-51.

Franklin KBJ, Paxinos G (2007) The mouse brain in stereotaxic coordinates, Ed 3. San Diego: Academic.

Franklin TR, Acton PD, Maldjian JA, Gray JD, Croft JR, Dackis CA, O’Brien CP, Childress AR (2002) Decreased gray matter concentration in the insular, orbitofrontal, cingulate, and temporal cortices of cocaine patients. Biol Psychiatry 51:134-142.

Garey L (2010) When cortical development goes wrong: schizophrenia as a neurodevelopmental disease of microcircuits. J Anat 217:324-333.

Ghashghaei HT, Barbas H (2001) Neural interaction between the basal forebrain and functionally distinct prefrontal cortices in the rhesus monkey. Neuroscience 103:593-614.

Ghashghaei HT, Hilgetag CC, Barbas H (2007) Sequence of information processing for emotions based on the anatomic dialogue between prefrontal cortex and amygdala. Neuroimage 34:905-923.

Giedd JN, Blumenthal J, Jeffries NO, Castellanos FX, Liu H, Zijdenbos A, Paus T, Evans AC, Rapoport JL (1999) Brain development during childhood and adolescence: a longitudinal MRI study. Nat Neurosci 2:861-863.

Gourley SL, Wu FJ, Kiraly DD, Ploski JE, Kedves AT, Duman RS, Taylor JR (2008) Regionally specific regulation of ERK MAP kinase in a model of antidepressant-sensitive chronic depression. Biol Psychiatry 63:353-359.

Gourley SL, Koleske AJ, Taylor JR (2009) Loss of dendrite stabilization by the Abl-related gene (Arg) kinase regulates behavioral flexibility and sensitivity to cocaine. Proc Natl Acad Sci U S A 106:16859-16864.

Gourley SL, Lee AS, Howell JL, Pittenger C, Taylor JR (2010) Dissociable regulation of goal-directed action within mouse prefrontal cortex. Eur J Neurosci 32:1726-1734.

Gourley SL, Taylor JR, Koleske AJ (2011) Cell adhesion signaling pathways: first responders to cocaine exposure? Commun Integr Biol 4:30-33.

Harris KM, Jensen FE, Tsao B (1992) Three-dimensional structure of dendritic spines and synapses in rat hippocampus (CA1) at postnatal day 15 and adult ages: implications for the maturation of synaptic physiology and long-term potentiation. J Neurosci 12:2685-2705.

Hernández SE, Settleman J, Koleske AJ (2004) Adhesion-dependent regulation of p190RhoGAP in the developing brain by the Abl-related gene tyrosine kinase. Curr Biol 14:691-696.

Homayoun H, Moghaddam B (2006) Progression of cellular adaptations in medial prefrontal and orbitofrontal cortex in response to repeated amphetamine. J Neurosci 26:8025-8039.

Homayoun H, Moghaddam B (2008) Orbitofrontal cortex neurons as a common target for classic and glutamatergic antipsychotic drugs. Proc Natl Acad Sci U S A 105:18041-18046.

Jentsch JD, Taylor JR (1999) Impulsivity resulting from frontostriatal dysfunction in drug abuse: implications for the control of behavior by reward-related stimuli. Psychopharmacology 146:373-390.

Kalivas PW, Alesdatter JE (1993) Involvement of N-methyl-D-aspartate receptor stimulation in the ventral tegmental area and amygdala in behavioral sensitization to cocaine. J Pharmacol Exp Ther 267:486-495.

Kalivas PW, Volkow ND (2005) The neural basis of addiction: a pathology of motivation and choice. Am J Psychiatry 162:1403-1413.

Kiraly DD, Ma XM, Mazzone CM, Xin X, Mains RE, Eipper BA (2010) Behavioral and morphological responses to cocaine require kalirin7. Biol Psychiatry 68:249-255.

Kolb B, Pellis S, Robinson TE (2004) Plasticity and functions of the orbital frontal cortex. Brain Cogn 55:104-115.

Kolb B, Cioe J, Comeau W (2008) Contrasting effects of motor and visual spatial learning tasks on dendritic arborization and spine density in rats. Neurobiol Learn Mem 90:295-300.

Koleske AJ, Gifford AM, Scott ML, Nee M, Bronson RT, Miczek KA, Baltimore D (1998) Essential roles for the Abl and Arg tyrosine kinases in neurulation. Neuron 21:1259-1272.

Krueger DD, Howell JL, Oo H, Olausson P, Taylor JR, Nairn AC (2009) Prior chronic cocaine exposure in mice induces persistent alterations in cognitive function. Behav Pharmacol 20:695-704.

Kuroda M, Murakami K, Igarashi H, Okada A (1996) The convergence of axon terminals from mediodorsal thalamic nucleus and ventral tegmental area on pyramidal cells in layer $\mathrm{V}$ of the rat prelimbic cortex. Eur J Neurosci 8:1340-1349.

Lee KW, Kim Y, Kim AM, Helmin K, Nairn AC, Greengard P (2006) Cocaine-induced dendritic spine formation in $\mathrm{D}_{1}$ and $\mathrm{D}_{2}$ dopamine receptor-containing medium spiny neurons in nucleus accumbens. Proc Natl Acad Sci U S A 103:3399-3404.

Lewis DA (1997) Development of the prefrontal cortex during adolescence: insights into vulnerable neural circuits. Neuropsychopharmacology 16:385-398.

Li N, Lee B, Liu RJ, Banasr M, Dwyer JM, Iwata M, Li XY, Aghajanian G, Duman RS (2010) mTOR-dependent synapse formation underlies the rapid antidepressant effects of NMDA antagonists. Science 329:959-964.

Liston C, Miller MM, Goldwater DS, Radley JJ, Rocher AB, Hof PR, Morrison JH, McEwen BS (2006) Stress-induced alterations in prefrontal cortical dendritic morphology predict selective impairments in perceptual attentional set-shifting. J Neurosci 26:7870-7874.

Liu RJ, Aghajanian GK (2008) Stress blunts serotonin- and hypocretinevoked EPSCs in prefrontal cortex: role of corticosterone-mediated apical dendritic atrophy. Proc Natl Acad Sci U S A 105:359-364.

Loftis JM, Janowsky A (2000) Regulation of NMDA receptor subunits and nitric oxide synthase expression during cocaine withdrawal. J Neurochem 75:2040-2050.

Mash DC, ffrench-Mullen J, Adi N, Qin Y, Buck A, Pablo J (2007) Gene expression in human hippocampus from cocaine abusers identifies genes which regulate extracellular matrix remodeling. PLoS One 2:e1187.

Moresco EM, Donaldson S, Williamson A, Koleske AJ (2005) Integrinmediated dendrite branch maintenance requires abelson (Abl) family kinases. J Neurosci 25:6105-6118.

Muhammad A, Kolb B (2011a) Mild prenatal stress modulated behavior and neuronal spine density without affecting amphetamine sensitization. Dev Neurosci 33:85-98.

Muhammad A, Kolb B (2011b) Maternal separation altered behavior and neuronal density without influencing amphetamine sensitization. Behav Brain Res 223:7-16

Norrholm SD, Bibb JA, Nestler EJ, Ouimet CC, Taylor JR, Greengard P (2003) Cocaine-induced proliferation of dendritic spines in nucleus accumbens is dependent on the activity of cyclin-dependent kinase-5. Neuroscience 116:19-22.

Ostlund SB, Balleine BW (2007) Orbitofrontal cortex mediates outcome encoding in pavlovian but not instrumental conditioning. J Neurosci 27:4819-4825.

Ostlund SB, Maidment NT, Balleine BW (2010) Alcohol-paired contextual 
cues produce an immediate and selective loss of goal-directed action in rats. Front Integr Neurosci 4:pii:19.

Ottersen OP (1982) Connections of the amygdala of the rat. IV: Corticoamygdaloid and intraamygdaloid connections as studied with axonal transport of horseradish peroxidase. J Comp Neurol 205:30-48.

Payne C, Machado CJ, Bliwise NG, Bachevalier J (2010) Maturation of the hippocampal formation and amygdala in Macaca mulatta: a volumetric magnetic resonance imaging study. Hippocampus 20:922-935.

Penzes P, Cahill ME, Jones KA, VanLeeuwen JE, Woolfrey KM (2011) Dendritic spine pathology in neuropsychiatric disorders. Nat Neurosci 14:285-293.

Peters A, Kaiserman-Abramof IR (1970) The small pyramidal neuron of the rat cerebral cortex. The perikaryon, dendrites and spines. Am J Anat 127:321-355.

Pierce RC, Kalivas PW (1997) A circuitry model of the expression of behavioral sensitization to amphetamine-like psychostimulatns. Brain Res Brain Res Rev 25:192-216.

Porrino LJ, Lyons D, Miller MD, Smith HR, Friedman DP, Daunais JB, Nader MA (2002) Metabolic mapping of the effects of cocaine during the initial phases of self-administration in the nonhuman primate. J Neurosci 22:7687-7694.

Pulipparacharuvil S, Renthal W, Hale CF, Taniguchi M, Xiao G, Kumar A, Russo SJ, Sikder D, Dewey CM, Davis MM, Greengard P, Nairn AC, Nestler EJ, Cowan CW (2008) Cocaine regulates MEF2 to control synaptic and behavioral plasticity. Neuron 59:621-633.

Quinlan EM, Philpot BD, Huganir RL, Bear MF (1999a) Rapid, experiencedependent expression of synaptic NMDA receptors in visual cortex in vivo. Nat Neurosci 2:352-357.

Quinlan EM, Olstein DH, Bear MF (1999b) Bidirectional, experiencedependent regulation of $\mathrm{N}$-methyl-D-aspartate receptor subunit composition in the rat visual cortex during postnatal development. Proc Natl Acad Sci U S A 96:12876-12880.

Rakic P, Bourgeois JP, Goldman-Rakic PS (1994) Synaptic development of the cerebral cortex: implications for learning, memory, and mental illness. Prog Brain Res 102:227-243.

Robinson TE, Kolb B (1997) Persistent structural modifications in nucleus accumbens and prefrontal cortex neurons produced by previous experience with amphetamine. J Neurosci 17:8491-8497.

Schoenbaum G, Setlow B, Saddoris MP, Gallagher M (2003) Encoding predicted outcome and acquired value in orbitofrontal cortex during cue sampling depends upon input from basolateral amygdala. Neuron 39:855-867.

Schoenbaum G, Saddoris MP, Ramus SJ, Shaham Y, Setlow B (2004) Cocaine-experienced rats exhibit learning deficits in a task sensitive to orbitofrontal cortex lesions. Eur J Neurosci 19:1997-2002.
Schumann J, Yaka R (2009) Prolonged withdrawal from repeated noncontingent cocaine exposure increases NMDA receptor expression and ERK activity in the nucleus accumbens. J Neurosci 29:6955-6963.

Sfakianos MK, Eisman A, Gourley SL, Bradley WD, Scheetz AJ, Settleman J, Taylor JR, Greer CA, Williamson A, Koleske AJ (2007) Inhibition of Rho via Arg and p190RhoGAP in the postnatal mouse hippocampus regulates dendritic spine maturation, synapse and dendrite stability, and behavior. J Neurosci 27:10982-10992.

Shen HW, Toda S, Moussawi K, Bouknight A, Zahm DS, Kalivas PW (2009) Altered dendritic spine plasticity in cocaine-withdrawn rats. J Neurosci 29:2876-2884.

Sherren N, Pappas BA (2005) Selective acetylcholine and dopamine lesions in neonatal rats produce distinct patterns of cortical dendritic atrophy in adulthood. Neuroscience 136:445-456.

Singer BF, Tanabe LM, Gorny G, Jake-Matthews C, Li Y, Kolb B, Vezina P (2009) Amphetamine-induced changes in dendritic morphology in rat forebrain correspond to associative drug conditioning rather than nonassociative drug sensitization. Biol Psychiatry 65:835-840.

Spear LP (2000) The adolescent brain and age-related behavioral manifestations. Neurosci Biobehav Rev 24:417-463.

Stalnaker TA, Takahashi Y, Roesch MR, Schoenbaum G (2009) Neural substrates of cognitive inflexibility after chronic cocaine exposure. Neuropharmacology 56 [Suppl 1]:63-72.

Toda S, Shen HW, Peters J, Cagle S, Kalivas PW (2006) Cocaine increases actin cycling: effects in the reinstatement model of drug seeking. J Neurosci 26:1579-1587.

Ujike H, Tsuchida H, Kanzaki A, Akiyama K, Otsuki S (1992) Competitive and non-competitive $N$-methyl-D-aspartate antagonists fail to prevent the induction of methamphetamine-induced sensitization. Life Sci 50:1673-1681.

Van Eden CG, Uylings HB (1985) Postnatal volumetric development of the prefrontal cortex in the rat. J Comp Neurol 241:268-274.

Vanderschuren LJ, Pierce RC (2010) Sensitization processes in drug addiction. Curr Top Behav Neurosci 3:179-195.

Wang HD, Deutch AY (2008) Dopamine depletion of the prefrontal cortex induces dendritic spine loss: reversal by atypical antipsychotic drug treatment. Neuropsychopharmacology 33:1276-1286.

Wiggins AT, Pacchioni AM, Kalivas PW (2009) Integrin expression is altered after acute and chronic cocaine. Neurosci Lett 450:321-323.

Yashiro K, Philpot BD (2008) Regulation of NMDA receptor subunit expression and its implications for LTD, LTP, and metaplasticity. Neuropharmacology 55:1081-1094

Zuo Y, Yang G, Kwon E, Gan WB (2005) Long-term sensory deprivation prevents dendritic spine loss in primary somatosensory cortex. Nature 436:261-265. 